\title{
Regional Security Complex: The Macedonian Context
}

\author{
Fatmir M. Xheladini
}

\begin{abstract}
The traditional concepts of security analysis addresses concerns that deal with security at the state level leaving ample room for the concerns regarding security aspects that are not addressed through these lenses appropriately. The challenges that international system of security is facing range in variety from ones that are different in form to the time sequence that they appear in a different space and geographical location. These may include factors that are objective and subjective and as such they characterize the nature of relationships between states. Behavior of the states may at times include an action that conceptualizes within a geographical framework based on attributes that states poses. Given this, Buzan has presented the idea of security complex that is defined as a group of states in which perceptions and key concerns over security are interrelated. In this context the security complex is tied together through geographical, political, historical economic and cultural issues amongst others. Hence regional issues have an important role in the building of security logic for countries individually or in a group and may impact the formulation of policies internally or externally. Based on these considerations in this article we analyze the security issues of Macedonia and how they reflect upon the wider security agenda of the countries in the region in a two-way reflection.
\end{abstract}

Keywords: Regional Security, Macedonia, Security.

\section{Introduction}

Since it started the process of seeking its independence from the Yougoslav Fedaration, Macedonia has undertaken some essential transformation that have had two way implications in terms of its security paradigms. In its quest for independence the potential fears of security impact have been both internal as well as regional.

The regional implications have played an important role in consolidation of the statehood as its potential internal destabilization may have had an impact on regional stability. On the other hand, the volatility in the region may have had an impact on its internal security as well.

Each of these challenging transformations constituted strategic and fundamental opportunities that have taken Macedonia on the brink of membership in NATO and the European Union. These achievements have reduced the dilemma of its ability not only to constitute a proper functioning democracy but also through these important memberships to provide a larger umbrella for its security challenges and economic performance. Both of these processes can be considered threats if the state institutions are unable to respond, and as opportunities if the state institutions and the political elite find the courage and means to move forward through the given framework to become members in the aforementioned organizations.

The importance of gaining membership in the aforementioned institutions becomes evident due to the perceived external security dilemmas that it faced in the early 1990's. These dilemmas were seen as important segment of policy choice in the establishment of the country in the international and regional organizations. The path that Macedonia underwent in achieving its international recognition was impacted by issues that at times were generating enmity and amity amongst the surrounding countries. Different issues were regarded differently from the regional countries based on the historical perceptions of each not excluding Macedonia itself. AS result of these issues Macedonia failed to gain a membership in the United Nations and subsequently other international organizations due to the veto by Greece. Although Bulgaria recognized the existence of the state it failed to make recognition of the Macedonian language and a distinct ethnic group. These challenges pressed the leaders of the country in direction of policy making that external security issues it faced to become domestic as well. The inclusion of all citizens in the building of state security is necessary, especially in a multiethnic state as Macedonia. 
Security Complex Theory has a special significance because it tends to apply a medium level of analysis, linking together two other levels, micro and macro level. The combination of the two would provide a more comprehensive and suitable analytical approach for certain countries or regions based on their historical experience or geographical location. In this regard it can be stated that between levels there is a mutual interaction where local security concerns can be transformed into international ones and vice versa. At times when international system becomes decentralized new actors and issues generate influences into the system.

These changing dynamics have given rise to the debate of widening and broadening the security concepts as opposed to what they were known in a more traditional or classical concepts. As the debate ranged so the approaches that sought to give an analytical tool to the concerns and issues that needed to be analyzed in a changing international environment of the post-cold war era.

In its initial stages, Security Complex Theory, or what is known in a more classical manner focuses on the state as the main actor of the international system. But as a result of the intensification and broadening of the concept of security, this theory was reprocessed again by its creators, creating two categories; homogeneous and heterogeneous complexes. Homogeneous complexes - formed while maintaining the basic logic of classical theory. While heterogeneous complexes - go beyond the logic of classical theory and argued that regional logic can integrate different types of actors who interact in two or more sectors (Buzan, Waever, \& Wilde, 1998, pp. 16-17).

Regional Security Complexes allow us to focus upon groupings of states whose actions dominate the security considerations of other member states. To further enhance this approach, Buzan and Waever in their work define a regional security complex as "...a set of units whose major processes of securitization, de-securitization, or both are so interlinked that their security problems cannot reasonably be analyzed or resolved apart from one another" (Buzan \& Weaver, 2003, p. 44).

For the purposes of our paper we further expand on the above definition to better understand the dynamics of impact of ach of the members or actor by having the focus on the external factors determine the actions of the other with the description that is given by Lake and Morgan that drives the regional security complex in a way that "...the members are so interrelated in terms of their security that actions by any member, and significant security-related developments inside any member, have a major impact on the others." (Lake \& Morgan, 1997, p. 12)

Regional Security complex theory as such has a variation of approaches that have blended together to form a multidimensional inputs between a more neorealist and constructivist composition. While the structural approach has a neorealist approach it indicates the beginning of a regional motivation to the global structure. The geographical implication to constructing the global level approach still maintains a sense of regionalism in getting the actions higher up. On the other hand, the constructivist approach has a tendency to shift its focus on the process that may affect the character of security relations. Thus the political process that constitutes the security issues essentially has subjective aspects that determine the potential relations between the actors. (Buzan \& Weaver, 2003, p. 4)

To have a better understanding of the regional security complex it is valuable to look at the variety of the states that constitute the group of states and what dynamics of interplay between those states is occurring. The democratic peace theory contends that democratic states do not tend to go to war rather solve their problems in peaceful means gives another window to the approach that needs to be viewed. Hence the political culture of the region may affect the means through which security concerns of each state are constructed. Hence Regional security complex theory makes a distinction from stable developed countries and unstable underdeveloped ones (Buzan \& Weaver, 2003, p. 21).

For the purposes of the paper the concept of collective security becomes evident. The concept first highlighted by Deutsch, incorporates the fact that the disagreements and the choice to solving them is by excluding violence and use of force. As suggested the Concept of collective security provides that the group of subjects who integrate to the extent that between them is mutual conviction that members of one or another society-group will not impose their interests by force, but in other ways. Hence the concept of security community means that in the international arena, states may share similar values, norms and symbols with which they still retain their separate identity. In addition to this conclusion goes the fact that in international relations, states are linked through interactions of different sectors including security, and can share common interests, reciprocity to build trust or otherwise constantly deal with mutual fear and mistrust (Deutch, 1957). 
As in earlier statements regions are an important segment of international system and further from the classical theories the Regional security complex considers the regions not only in geographical and material terms but also as interlinked to the degree that the fear of one state affects the other one through a web of issues that may not be considered separate.

The region, in contrast, refers to the level where states or other units link together sufficiently closely that their securities cannot be considered separate from each other. This degree of interdependence differs from one region to the other and the nature of political system that dominates in the region. The impact and influence of global politics in the regional context makes the complex an important security structure in which the action of a unit within the region may spur fear in another unit. The crossing of the global and the state unit interplay creates a level worthy of analysis. This intersection of security dynamics requires additional outlook on the reasons and sources that create the interdependence in terms of security between these units (Buzan \& Weaver, 2003, p. 43).

The paper has in consideration that Macedonia as such falls further into a sub complex. The concept goes further in the extension of the regional security complex where the security interdependence is intensive from the inside. A sub complex is engaged from within but also has a segment which constitutes a security complex larger than what can be understood from the interactions of the subgroup (Buzan \& Weaver, 2003, p. 51).

\section{Macedonian Context}

The perceived external security dilemmas that it faced in the early 1990's, served as a justification for the leadership of the country to undertake actions that incorporated policies that were having influence not only in the foreign- regional relations but also those of internal actors.

Macedonia failed to gain a membership in the United Nations and subsequently other international organizations due to the veto by Greece. Although Bulgaria recognized the existence of the state it failed to make recognition of the Macedonian language and a distinct ethnic group. The issues pertaining to the succession with Serbia included a range of segments but most pressing from a regional contexts being that with the Church. On the other hand the large Albanian community was feeling not completely included in the new shaping of the state and as such posing a range of concerns from inside. These challenges pressed the leaders of the country in direction of policy making that external security issues it faced to become domestic as well.

From the moment of its independence the row has extended to include not only the denomination of the country but also the symbols that initially Macedonia used to strengthen its national identity. The contest is not new and it has resurfaced continuously since the end of 19 th century as a contented issue of resurgent nationalisms in the Balkans when the demise of Turkish rule was coming to a close. When Macedonia proclaimed its independence and was applying for membership in International Organizations the problem resurfaced as the opposition to its membership in these organizations was blocked (Craven, 1996).

The identity security dilemma for Macedonia has derived from the dispute of the existence of identity of Macedonian ethnic group as a separate identity. The contest with Greece over the name Macedonia which is also a major region in northern Greece has touched upon the neighborly relations of Macedonia with almost all of its bordering neighbors. Although the name issue that is contested by Greece is well known as a state problem, the disputed existence of Macedonian language by Bulgaria is equally exerting pressure to the Macedonian ethnic political elite. The Bulgarian and Serbian perception are connected to the context of the ethnic origin of Macedonians and its church. The Bulgarian and Serbian claims to the origins and belonging of the Macedonian identity has exerted considerable pressure on internal stability of the country whereas the name issue with Greece has kept Macedonia away from important memberships in NATO and EU. (Engstrom, March 2002, vol.1 nr 3).

These segments of external pressure from the regional context have exerted pressure to the Macedonian political actors to take a course that in effect generate policies impacting internal stability of Macedonia. The origin of the problem has been from the external factors but the political elite in its quest to consolidate the state from inside has taken measures that have regenerated resentments from the groups inside the country. The pressure is visible when it comes to making decisions at domestic level as well as when those pertain to foreign policies. As consequence independence of Macedonia was based around the construction of single ethno cultural state through which civic liberties were pushed aside and ethnic resentment was evident throughout (Ragaru, January 2008). 


\section{Conclusions}

From what has been presented above we can see that in the case of Macedonia security concerns of one state are becoming issues of another one. Issues that concern one country at times generate political moves of securitization or desecuritization that cannot be analyzed or solved separately. From this perspective we may say that regional security subcomplex as in the case of Macedonia is so much interrelated in terms of security between the various members that important security issues in one country can have impact on the other country.

We can see that regional implications for Macedonia have played an important role in its quest for independence and after it. These implications have played a role be that in social or cultural issues that are interrelated between the countries in question. The political choices that have been made by the Macedonian political elite have played an important role in constituting the opportunities of gaining a membership in larger regional organizations but as well in its economic performance.

\section{References}

[1] Buzan, B. (1991). New Patterns of Global Security in the Twenty First Century. International Affairs, 431-435.

[2] Buzan, B., \& Weaver, O. (2003). Regions and Powers. Cambridge: Cambridge University Press.

[3] Buzan, B., Waever, O., \& Wilde, J. D. (1998). Security: A New Framework For Analysis. London: Lynne Reinner Publishers.

[4] Craven, M. C. (1996). What's in a Name? Australian Yearbook of International Law.

[5] Deutch, K. W. (1957). Political Community and the North Atlantic Area. International Organization in the Light of Historical Experience. Princeton: Princeton university press.

[6] Engstrom, J. (March 2002, vol.1 nr 3). The Power of Perception, the Impact of Macedonian Question on Interethnic relations in The Republic of Macedonia. The Global Review Of Ethnopolitics, 3-17.

[7] Lake, D. A., \& Morgan, P. M. (1997). Regional Orders: Building Security in a New World. University Park : Pennsylvania State University.

[8] Ragaru, N. (January 2008). Macedonia: Between Ohrid and Brussels.

[9] Waever, O., Buzan, B., Kelstrup, M., \& Lemaitre, P. (1993). Identity, Migration and the New Security Agenda In Europe. New York: St. Martins Press. 